\title{
MUDANÇA DO CLIMA E SEUS IMPACTOS NO SEGURO AGRÍCOLA NO BRASIL
}

\author{
Thais Camolesi Guimarães* \\ Alexandre Toshiro Igari**
}

RESUMO: O presente artigo tem por objetivo avaliar a possibilidade de ocorrência de seleção adversa no mercado de seguro agrícola no Brasil. A seleção adversa ocorre quando os seguros são prioritariamente contratados por agentes com maior risco de sinistro. A hipótese é que tal fenômeno poderia ser deflagrado pelo aumento do valor indenizado em sinistros decorrentes de eventos climáticos extremos, que provocaria posteriormente aumento nos prêmios cobrados pelas empresas seguradoras. Os prêmios mais caros fazem com que as carteiras passem a ser compostas prioritariamente por segurados de maior risco, o que aumentaria ainda mais a recorrência de indenizações a sinistros. Para atender ao objetivo proposto, realizaram-se análises de regressão linear entre sinistros ocorridos em um ano e as contratações no ano seguinte, entre o período de 2003 a 2013, para seis Unidades Federativas do Brasil, sendo elas: Mato Grosso do Sul (MS); Minas Gerais (MG); Paraná (PR); Santa Catarina (SC); Rio Grande do Sul (RS); e São Paulo (SP). A significância das regressões lineares dos dados foi estimada por meio de testes estatísticos de aleatorização. Para os Estados de MS, RS e SP foi possível inferir a ocorrência de seleção adversa no período de 2003 a 2013. Os resultados contribuem para a caracterização e identificação do fenômeno de seleção adversa, que pode causar perdas substanciais do mercado de seguro agrícola no Brasil.

PALAVRAS-CHAVE: Adaptação; Eventos climáticos extremos; Mudança do clima; Seguro agrícola; Seleção adversa.

\section{CLIMATE CHANGE AND ITS IMPACTS ON AGRICULTURAL INSURANCE IN BRAZIL}

ABSTRACT: The possibility of an occurrence of adverse selection in the agricultural insurance market in Brazil is evaluated. Adverse selection occurs when insurances are primarily contracted by agents, at high risks. The hypothesis is that the phenomenon

\footnotetext{
${ }^{*}$ Fundação Getulio Vargas. Centro de Estudos em Sustentabilidade - FGVces, Brasil.

${ }^{* *}$ Universidade de São Paulo - Escola de Artes, Ciências e Humanidades - EACH-USP. Programa de Pós Graduação em Sustentabilidade, Brasil. E-mail: alexandre.igari@usp.br
} 
may be triggered by increase in value compensated in accidents derived from extreme climate changes that would cause increase in the premiums demanded by the insurance companies. The most expensive premiums cause portfolios to be primarily composed of high-risk insurance, increasing the occurrence of compensation for losses. Linear regression analyses were performed between losses, which occurred in one year, and contracts for the following year, between 2003 and 2013 for six Brazilian states: Mato Grosso do Sul (MS); Minas Gerais (MG); Paraná (PR); Santa Catarina (SC); Rio Grande do Sul (RS); and São Paulo (SP). The significance of data linear regressions was estimated by randomized statistical tests. The occurrence of adverse selection between 2003 and 2013 could be inferred in the case of the states of MS, RS and SP. Results contribute towards the characterization and identification of the adverse selection phenomenon that causes high loss rates in the Brazilian agricultural insurance market.

KEYWORDS: Adaptation; Extreme climate events; Climate change; Agricultural insurance; Adverse selection.

\section{INTRODUÇÃO}

Um dos principais problemas relacionados à mudança do clima é que esta leva a um aumento da intensidade e frequência de eventos climáticos extremos, como ondas de calor, secas, nevascas e tempestades (MANAGING, 2012). Os crescentes custos econômicos destes eventos extremos vêm promovendo a disseminação dos instrumentos de mitigação e adaptação. A concepção e implementação destes instrumentos devem incorporar a variabilidade geográfica, social e econômica da vulnerabilidade à mudança do clima (MARENGO, 2009).

Nesse sentido, o setor agrícola merece especial atenção, por ser o setor econômico mais diretamente sensível ao clima, e que apresentaria perdas expressivas em quase todos os Estados brasileiros (ECONOMIA..., 2010). Considerando que o agronegócio contribui com 23\% do Produto Interno Bruto (PIB) nacional e 35\% dos empregos gerados no país (BRASIL, 2016), é fundamental incorporar no planejamento do setor o risco de ocorrência de eventos climáticos extremos, bem como os impactos econômicos associados.

Diante do aumento da frequência e intensidade da ocorrência de eventos climáticos extremos, acentua-se a expectativa de sinistros nas atividades agropecuárias. 
Diferentemente de outras modalidades de seguro, nas quais os eventos de sinistro são razoavelmente independentes entre os segurados, o seguro agrícola apresenta a especificidade do fenômeno de catástrofe, o qual expõe ao risco simultaneamente um grande número de segurados em uma mesma área (BUAINAIN; VIEIRA, 2011). Assim, aumenta-se a possibilidade de que eventos climáticos extremos de ampla distribuição geográfica resultem em um montante de indenizações aos sinistros superior aos valores totais dos prêmios pagos. O resultado pode comprometer substancialmente a viabilidade financeira das empresas seguradoras e resseguradoras.

Este cenário é vulnerável à ocorrência do fenômeno da seleção adversa. $\mathrm{O}$ maior risco de sinistro faz com que as companhias de seguros passem a cobrar prêmios maiores, e, como consequência, a carteira de seguros passa a ter predominância de clientes com maior risco associado (BOYER; PORRINI, 2008). Assim, é fundamental que o fenômeno de seleção adversa seja devidamente identificado, localizado e analisado, de maneira que seja possível estabelecer um prognóstico para sua reversão. Um possível prognóstico seria o incentivo a investimentos em adaptação à mudança do clima, o que reduziria o risco de sinistros e interromperia a espiral econômica negativa causada pela seleção adversa nos seguros agrícolas.

Diante desta problemática, o presente artigo objetiva responder se, diante à intensificação dos fenômenos climáticos extremos, ocorreria aumento da contratação de seguros e caracterização de seleção adversa no mercado de seguro agrícola no Brasil.

\subsection{REVISÃO TEÓRICA}

\subsubsection{Impactos da Mudança do Clima na Agricultura: Medidas de Mitigação e Adaptação para o Setor}

Os eventos climáticos extremos no Brasil são cada vez mais frequentes e geram perdas econômicas expressivas, as quais representam justificativas pragmáticas para que empresas e governos invistam em estratégias de mitigação e adaptação. De 1997 a 2016, é estimada uma perda média anual de US\$ 1,7 bilhões, representando 0,06\% do PIB do país (ECKSTEIN; KÜNZEL; SCHÄFER, 2017). 
Além dos impactos gerados pelos eventos climáticos extremos, os quais são perceptíveis a curto prazo, é importante considerar também o cenário de impactos da mudança do clima a um horizonte de médio e longo prazo. Dentre os diversos setores econômicos do Brasil, a agropecuária é o setor mais diretamente sensível ao clima, com uma projeção de queda de produção correspondente a 2,5\% em um cenário mais otimista, e de 4,5\% em um cenário mais pessimista em relação ao PIB agropecuário projetado para 2050 (ECONOMIA..., 2010).

Os efeitos econômicos diretos podem ser multiplicados por quatro ao levarem-se em consideração os efeitos sistêmicos destes eventos extremos, como impactos na cadeia produtiva do agronegócio, nos custos de produção e nos preços agrícolas, o que resulta em impactos negativos na competitividade da produção brasileira no mercado internacional e também no poder de compra no mercado interno (HADDAD, 2013).

Assim, os eventos extremos podem atingir pontos vulneráveis nas cadeias produtivas do agronegócio, resultando na necessidade de que os agentes econômicos adotem medidas para preservar a eficiência operacional e o crescimento da produção agropecuária (LOVATELLI, 2011).

Existem duas grandes frentes de esforços sobre a mudança do clima recomendadas pelo IPCC: adaptação e mitigação. A mitigação tem por objetivo reverter ou eliminar os impactos causados por um evento, através de medidas ou ações que reduzam os impactos negativos causados ao ambiente. Para tanto, se estabelecem prazos de implantação e execução com metas e objetivos específicos (WORLD METEOROLOGICAL, 2014).

A adaptação, por sua vez, tem por objetivo estabelecer medidas imediatas que permitam conviver com os impactos negativos causados pela mudança climática. Ou seja, complementarmente à mitigação, a adaptação propõe medidas que não visam propriamente à redução dos impactos ambientais, mas sim a assimilação destes impactos pela sociedade. Através das medidas de adaptação ocorre a redução da vulnerabilidade social aos impactos negativos, apesar do evento climático e seus efeitos permanecerem ocorrendo (WORLD METEOROLOGICAL, 2014).

Um instrumento relevante na relação entre mudança do clima e agricultura, tanto para mitigação quanto adaptação, é o Plano Setorial de Agricultura de Baixa 
Emissão de Carbono (Plano $\mathrm{ABC}$ ), um dos planos setoriais que constitui a Política Nacional sobre Mudança do Clima. Criado em 2011, o Plano ABC prevê recursos da ordem de $\mathrm{R} \$ 4$ bilhões por ano safra, até 2020 , para que a agricultura brasileira adote técnicas de baixa emissão de gases de efeito estufa (GEE).

O Plano ABC prevê estímulo financeiro e tecnológico a medidas voltadas à redução das emissões de GEE como: redução/eliminação do desmatamento, reflorestamento, utilização de biocombustíveis e transição para uma matriz energética limpa (ASSAD, 2007; ECONOMIA..., 2010).

Além de seu objetivo de mitigação, o Plano também tem por objetivo apoiar o setor agropecuário na implementação de ações de adaptação, aumentar a resiliência dos agroecossistemas e fomentar o desenvolvimento e transferência de tecnologias (BRASIL, 2016).

No que diz respeito às medidas de controle dos riscos climáticos, as quais são fundamentais para reduzir a recorrência de sinistros no seguro agrícola, destacase que, no Brasil, o principal instrumento de política agrícola para gestão e controle de riscos é o Zoneamento Agrícola de Risco Climático, revisado anualmente e divulgado pelo Ministério da Agricultura, Pecuária e Abastecimento (MAPA).

O Zoneamento Agrícola de Risco Climático é elaborado com o objetivo de minimizar os riscos relacionados aos fenômenos climáticos e permite a cada município identificar a melhor época de plantio das culturas, nos diferentes tipos de solo e ciclos de cultivares (BRASIL, 2014a). O zoneamento "[...] permite determinar a melhor época de semeadura para cada município, onde as fases mais críticas da cultura tenham uma probabilidade menor de coincidirem com as adversidades climáticas" (INSTITUTO NACIONAL DE PESQUISAS ESPACIAIS, 2017).

Outra importante estratégia de controle de riscos é o aprimoramento de sistemas de previsões climáticas, uma vez que no Brasil há poucas estações meteorológicas que podem prever mudanças no clima com razoável grau de certeza. O monitoramento das condições climáticas tem se tornado cada vez mais importante, considerando-se os impactos previstos da mudança do clima na agricultura (GUANZIROLI; BASCO, 2008).

Para tentar entender as mudanças na probabilidade da ocorrência de eventos climáticos extremos sob cenários de mudança do clima, as seguradoras, 
gradativamente, passam a fundamentar-se no conhecimento científico e nas modelagens climáticas, complementarmente a suas bases de dados históricos de perdas relacionadas aos eventos climáticos, para melhor quantificar e diversificar sua exposição a riscos, passando a precificar e comunicar o risco de forma mais precisa e oferecendo bases para adaptação e prevenção de perdas (MILLS, 2012).

O Plano Nacional de Adaptação à Mudança do Clima, lançado em 2016, tem a agricultura como um de seus onze setores alvo, propondo medidas de adaptação gerais dentro do Programa de Adaptação para a Agricultura, as quais:

Envolvem sistemas de informação mais ágeis e estruturados conforme o público (pesquisa, desenvolvimento de políticas públicas ou setor produtivo), monitoramento e informações quanto ao uso da terra, pesquisa em diversas frentes, instrumentos financeiros, mecanismos de desenvolvimento rural e políticas públicas voltadas para fortalecer o setor frente às mudanças do clima (BRASIL, 2016, p. 28).

\subsubsection{Seguro Agrícola no Brasil e Seleção Adversa}

A primeira experiência de seguro agrícola no Brasil em âmbito nacional foi em 1954, com a criação da Companhia Nacional de Seguro Agrícola. Já em 1973, foi criado o Programa de Garantia da Atividade Agropecuária (Proagro). Visando atender aos pequenos e médios produtores, o Proagro "garante a exoneração de obrigações financeiras relativas à operação de crédito rural de custeio, cuja liquidação seja dificultada pela ocorrência de fenômenos naturais, pragas e doenças que atinjam rebanhos e plantações" (BRASIL, 2014b).

Até a criação do Proagro, o governo federal atuava como o único garantidor de perdas em anos de calamidade. Em anos em que ocorriam eventos extremos, para evitar a insolvência generalizada entre os agricultores, era necessário cancelar indiscriminadamente as dívidas dos mesmos. Já em casos de perdas localizadas, adotava-se o adiamento do pagamento das dívidas (HAZELL; POMAREDA; VALDÉS, 1986).

Em 2005 houve um avanço no setor, com a implementação de um programa de seguro agrícola replicado do modelo dos EUA, o Programa de Subvenção ao Prêmio 
do Seguro Rural (PSR). Com este modelo, o governo passou a fornecer subsídios de $40 \%$ a $60 \%$ para os prêmios, o que contribuiu para reduzir os desembolsos pelos agricultores, tornando o seguro mais atraente (THE RISE..., 2014).

No início das operações do PSR, este beneficiava sete culturas na modalidade agrícola, sendo que em 2006 a assistência foi ampliada para um número maior de culturas agrícolas e incluiu também outras modalidades de seguro rural (pecuária, florestal e aquícola) (MITIDIERI; MEDEIROS, 2008). O estabelecimento do PSR contribuiu para o crescimento do seguro agrícola no Brasil, com um aumento da área plantada coberta pelo seguro de 0,1\% em 2005 (THE RISE..., 2014) para 15\% em 2017 (ANDRADE, 2017).

O seguro agrícola no Brasil concentra-se nas regióes de cultivo no Sul, onde os riscos climáticos são altos, com destaque também para os Estados de São Paulo, Mato Grosso do Sul e Minas Gerais. Já na região Norte, no Centro-Oeste e partes do Sudeste e do Nordeste, há uma baixa adesão ao seguro agrícola (SANTOS; SOUSA; ALVARENGA, 2013). Isso porque, nas regióes Norte, Centro-Oeste e Sudeste, a regularidade e previsibilidade histórica das condições climáticas implicam em riscos menores e possível desinteresse no seguro agrícola, enquanto que na região Nordeste, a alta vulnerabilidade a eventos de seca faz subir os prêmios, desincentivando a contratação dos seguros devido aos altos preços das apólices.

A limitada abrangência territorial e as desigualdades regionais evidenciam a incipiência tanto do mercado de seguros como do PSR. Outro fator que tem afetado negativamente o desenvolvimento do seguro agrícola é que este sistema vem oferecendo coberturas contra todos os tipos de risco (como inundações, granizo, seca e pragas), em um país onde o contexto ambiental varia muito de região para região.

A indisponibilidade de seguro também afeta o crédito rural, pois sem o seguro aumenta-se o risco de insolvência dos agricultores em seus financiamentos e empréstimos (SCHELSKE et al., 2009), fazendo com que os bancos passem a ser ainda mais cautelosos para conceder crédito aos agricultores, para protegerem-se de perdas decorrentes de sinistros ou mesmo por falência destes clientes.

É importante ainda destacar que a disponibilidade limitada do seguro agrícola em países em desenvolvimento representa um tema de relevada importância, 
considerando que os países em desenvolvimento são caracterizados por uma elevada vulnerabilidade a riscos climáticos e apresentarem baixa capacidade adaptativa (PANDA et al., 2013). O aprimoramento e ampliação do sistema de seguro agrícola tem potencial para melhorar a capacidade de adaptação dos grupos mais vulneráveis.

Há diversos tipos de riscos relacionados à agricultura, sendo que para o Brasil estes são divididos em três grupos: riscos de produção, riscos de mercado e riscos do ambiente de negócios (BANCO MUNDIAL, 2015). Dentro do grupo de riscos de produção está o risco climático, que é inerente à agricultura.

Como a agricultura se constitui como um elo básico na estrutura de produção do país, a ocorrência de eventos climáticos extremos resulta em um efeito multiplicador dos prejuízos econômicos ao longo da cadeia de valor, afetando direta e indiretamente outros setores da economia, como comércio e indústria, e com efeitos persistindo durante alguns anos após sua ocorrência (BUAINAIN; VIEIRA, 2011).

Nesse sentido, as políticas agrícolas foram criadas para tentar minimizar os impactos econômicos das perdas das atividades do setor. Um dos principais instrumentos de compensação dos prejuízos na agricultura é o seguro rural, pois este permite ao produtor proteger-se contra perdas decorrentes de fenômenos climáticos adversos (SUPERINTENDÊNCIA DE SEGUROS PRIVADOS, 2014a).

$\mathrm{O}$ seguro rural cobre não apenas a atividade agrícola. Este visa oferecer coberturas que reduzam os riscos de todos os stakebolders envolvidos na cadeia de valor, desde o produtor até seus financiadores e parceiros de negócio. O seguro agrícola, por sua vez, é uma modalidade do seguro rural que cobre especificamente as atividades agrícolas - desde a semeadura e emergência da planta até a colheita - contra perdas decorrentes principalmente de fenômenos meteorológicos (SUPERINTENDÊNCIA DE SEGUROS PRIVADOS, 2014a).

No Brasil, existem quatro tipos de seguro agrícola (ALMEIDA, 2017). O seguro de danos oferece garantias contra riscos específicos, como geadas e granizo, e cobre apenas os riscos com maior probabilidade de ocorrência em cada região. $\mathrm{O}$ seguro de produtividade indeniza a diferença entre a produção garantida e a obtida com base em um preço fixo, apresentando um elevado custo administrativo, por requerer conhecimento da produtividade individual histórica de cada agricultor. 
Já o seguro de renda é determinado pelo comportamento do mercado e cobre tanto os riscos climáticos como os de oscilação de preço e produtividade, tendo um custo elevado de contratação. Por fim, há o seguro de índice ou paramétrico, em que as indenizações são pagas em função do comportamento de uma variável prédeterminada, como pluviosidade ou temperatura. Por voltar-se ao controle regional ou microrregional dos riscos relacionados com fenômenos climáticos, este tipo de seguro tem um custo operacional significativamente menor que os demais modelos fundamentados na análise individual dos produtores.

Apesar da variedade de esquemas de seguro agrícola, existem poucos sistemas de seguro em larga escala no mundo, pois há quatro elementos que dificultam a expansão do seguro agrícola. O primeiro deles é o fato de que o cálculo preciso da probabilidade de frustração de safra é bastante complexo, pois diversas variáveis sem distribuição definida permeiam a função de probabilidade de ocorrência de eventos que influenciam a produção agrícola (CUNHA, 2002).

O segundo elemento é o alto custo de monitoramento da evolução da safra, associado à recorrência de risco moral. No caso de sinistro, frequentemente é difícil diferenciar o que é realmente consequência dos eventos extremos - ou de outros fenômenos da natureza - daquilo que configura-se como risco moral, fruto da má fé ou imperícia do produtor (BOYER; PORRINI, 2008).

O terceiro elemento é o risco sistêmico ou risco de evento generalizado. Em outras modalidades de seguro os eventos são razoavelmente independentes entre os segurados, mas no caso da agricultura existe o fenômeno de catástrofe, que expõe ao risco simultaneamente um grande número de segurados em uma mesma área (BUAINAIN; VIEIRA, 2011).

Ao afetar um grande número de segurados ao mesmo tempo, as seguradoras podem ser incapazes de indenizar todos os sinistros. Nesse sentido, o equilíbrio financeiro de um pool de seguros é dado pela relação entre os valores agregados de prêmios pagos pelos segurados e as indenizações de sinistros (LOTZE-CAMPEN; SCHELLNHUBER, 2009). Assim, a gestão eficiente de seguros demanda uma carteira ampla e diversificada para poder equilibrar os custos e as receitas das seguradoras, havendo um tamanho de carteira e uma dispersão de risco mínima para que uma empresa seguradora consiga manter sua viabilidade econômica diante da ocorrência de eventos extremos. 
Por fim, o quarto elemento é o fenômeno de seleção adversa. Caso ocorra um aumento no montante de indenizações a sinistros, para manter sua viabilidade econômica, a companhia de seguros passaria a cobrar prêmios mais elevados. $\mathrm{O}$ aumento no valor dos prêmios pode fazer com que a carteira de segurados passe a ser composta predominantemente pelos clientes com maior risco, o que reduz a diversificação e expõe a seguradora a uma probabilidade ainda maior de aumento dos sinistros indenizados (BOYER; PORRINI, 2008).

$\mathrm{O}$ fenômeno de seleção adversa pode alimentar uma espiral econômica negativa, onde cada ciclo acaba levando a uma maior perda na carteira de seguros, resultante do crescente desequilíbrio entre volumes de sinistros e prêmios, e também em função da redução da diversidade de risco dos contratantes, com a predominância de riscos altos.

Esses quatro elementos em conjunto configuram um cenário de informação incompleta para as transações entre seguradoras e segurados, que resulta em redução na eficiência no funcionamento dos mercados de seguro agrícola (MEIRELES, 2010). Esta falha de mercado torna necessária a atuação do Estado como apoiador e indutor do mercado de seguro agrícola, com o intuito de incrementar sua eficiência por meio da redução de assimetrias e do aprimoramento das informações relevantes para as transações.

\section{MÉTODOS}

De acordo com uma revisão de literatura feita por Richards e Michen (1998), testes empíricos de seleção adversa utilizam, tipicamente, estimativas da resposta dos participantes aos retornos do seguro (indenização a sinistros) ou ao custo de contratar o seguro (prêmios). Nesse sentido, "uma resposta positiva aos sinistros, ou uma resposta negativa aos prêmios, é interpretada como evidência de seleção adversa" (RICHARDS; MICHEN, 1998, p. 54, tradução nossa).

Assim, o indicador selecionado para identificar a ocorrência de seleção adversa no seguro agrícola no Brasil é a influência exercida pelo valor total de sinistros ocorridos em um ano sobre as contratações de seguro do ano seguinte, representados pelo valor total dos prêmios pagos. O valor total de sinistros representa 
uma proxy para o aumento de riscos ambientais na carteira de seguro agrícola. $\mathrm{O}$ indicador de seleção adversa é evidenciado, desta maneira, pelo coeficiente de regressão linear $\left(\mathrm{R}^{2}\right)$ do conjunto de dados, onde: os sinistros totais pagos no ano corrente são a variável explicativa (x); e os prêmios totais pagos no ano posterior são a variável dependente (y). Quanto maior o valor de $\mathrm{R}^{2}$, maior seria a influência dos sinistros do ano corrente no valor dos prêmios pagos no ano posterior, o que fornece evidência de ocorrência do fenômeno de seleção adversa. A Tabela 1, a seguir, ilustra a estruturação dos dados dos prêmios e sinistros em uma Unidade Federativa, ano a ano, para a análise de regressão linear:

Tabela 1. Estruturação dos dados para análise de regressão linear entre os sinistros e os prêmios anuais pagos no seguro agrícola em cada Unidade Federativa

\begin{tabular}{cc}
\hline Sinistros $(\boldsymbol{x})$ & Prêmios $(\boldsymbol{y})$ \\
\hline 2012 & 2013 \\
\hline 2011 & 2012 \\
\hline 2010 & 2011 \\
\hline 2009 & 2010 \\
\hline 2008 & 2009 \\
\hline 2007 & 2008 \\
\hline 2006 & 2007 \\
\hline 2005 & 2006 \\
\hline 2004 & 2005 \\
\hline 2003 & 2004 \\
\hline
\end{tabular}

Para obter os dados para esta análise, foi feito um levantamento no SES - Sistema de Estatísticas da SUSEP (Superintendência de Seguros Privados), para cada Unidade Federativa (UF) do Brasil, do valor dos sinistros cobertos entre 2003 a 2012 e dos prêmios pagos entre 2004 a 2013. Esta série temporal, de dez anos, foi selecionada por abranger o principal período de evolução do Programa de Subvenção ao Prêmio do Seguro Rural (PSR), que se deu de 2006 a 2011 (SUPERINTENDÊNCIA DE SEGUROS PRIVADOS, 2014b).

Para algumas UFs, foram obtidos da base de dados do SES valores zerados para prêmios e/ou sinistros, e valores negativos para sinistros. Tais valores 
registrados como zero na base de dados são válidos para análise, representando ausência de operações, e não ausência do dado. Entretanto, tendo em vista que séries de dados com muitos zeros e valores negativos caracterizariam UFs com baixa representatividade no mercado de crédito agrícola, determinou-se como critério de seleção que seriam incluídas na análise somente as UFs que apresentassem as séries de dados completas e sem zeros, tanto de sinistros como de prêmios. Além disso, a inclusão de séries com muitos dados com valor igual a zero reduziria o poder explicativo da análise, prejudicando a interpretação dos resultados dos testes estatísticos aplicados aos dados.

De acordo com esses critérios de inclusão, do total de 27 UFs, foram selecionadas seis para análise, sendo elas: Mato Grosso do Sul (MS), Minas Gerais (MG), Paraná (PR), Rio Grande do Sul (RS), Santa Catarina (SC) e São Paulo (SP). Para cada uma das seis UFs, a partir da organização dos dados ilustrada na Tabela 1, foi realizada uma análise exploratória preliminar identificando o ano em que ocorreu o pico de sinistros e os períodos em que o valor de sinistros foi maior que o de prêmios. Na sequência, foram realizadas duas análises estatísticas no R Package (THE R FOUNDATION FOR STATISTICAL COMPUTING, 2017).

Primeiramente, foi realizada uma análise de regressão linear simples, cujo objetivo é, a partir de um modelo linear, descrever a relação entre uma variável dependente y (ou resposta) e uma variável independente $\mathrm{x}$ (ou explicativa) (LEGENDRE; LEGENDRE, 1998). Nesse contexto, o modelo de regressão é utilizado para se realizar uma inferência de causalidade, uma vez que se supõe, com base na hipótese de seleção adversa, que os sinistros ocorridos em um ano têm relação de causalidade sobre os prêmios pagos no ano posterior.

Após a análise de regressão, foi realizado um teste de aleatorização, o qual considera uma hipótese nula, de que a relação entre as variáveis não diverge de um padrão aleatório; e uma hipótese alternativa, a qual afirma que a relação entre as variáveis não é aleatória, apresentando neste caso um padrão linear (MANLY, 2007).

$\mathrm{Na}$ plataforma R (THE R FOUNDATION FOR STATISTICAL COMPUTING, 2017), foi calculado o coeficiente de regressão linear $R^{2}$ a partir da estrutura de dados original apresentada na Tabela 1 . Em seguida, foram realizadas para cada UF 10.000 aleatorizações dos dados, e, para cada aleatorização, foi calculado novamente 
$o R^{2}$. Desta maneira, foi possível calcular o percentual de vezes que, com ordenações ao acaso das séries de dados, o valor de $\mathrm{R}^{2}$ foi maior ou igual ao coeficiente de regressão original. Caso este percentual fosse superior ao nível de significância de 5\% (escolhido a priori), não seria possível refutar a hipótese nula, que aquele valor de $\mathrm{R}^{2}$ não difere significativamente do que seria obtido em combinações ao acaso da série de dados (MANLY, 2007).

No presente artigo, a hipótese nula é de que não existe relação linear estatisticamente significativa ( $\mathrm{p}$-valor $>0,05$ ) entre os sinistros e os prêmios pagos, o que implica na inexistência de seleção adversa. Já a hipótese alternativa é de que existe relação significativa de causalidade ( $\mathrm{p}$-valor $<0,05$ ), explicada por um modelo linear entre os sinistros e os prêmios pagos e assim, por extensão, existe seleção adversa.

A principal vantagem do teste de aleatorização é que ele pode ser utilizado para pequenos conjuntos de dados, sendo assim adequado para analisar as séries de dados deste estudo. Já a principal desvantagem deste teste é a impossibilidade de generalizar conclusões para o tema de interesse além dos dados que foram analisados (MANLY, 2007). Entretanto, o método permite descrever uma tendência que ocorreu no período de tempo analisado, permitindo a realização de inferência de causalidade entre as variáveis analisadas.

Outra limitação do estudo está no fato de que os resultados, com base nas informações disponibilizadas pela base de dados da SUSEP, dizem respeito a valores financeiros agregados de pagamento de sinistros e de prêmios cobrados. Esses valores agregados não são acompanhados pelo número de apólices contratadas, logo, não é possível identificar se estão sendo cobrados prêmios mais caros ou se houve um aumento no número de contratações. Os dados disponíveis permitem apenas identificar o efeito agregado destes dois processos. Caso estivesse disponível ao menos a informação de número anual de contratos, seria possível identificar o valor médio dos prêmios cobrados. Idealmente seria desejável dispor das informações de cada contrato individualmente, tanto sobre o valor do prêmio, quanto sobre a área assegurada, o tipo de cultivo e as medidas de adaptação adotadas. Tais informações enriqueceriam a análise e permitiriam investigar com maior detalhamento o fenômeno de seleção adversa a partir dos parâmetros propostos por Richards e 
Michen (1998), que são o aumento de risco médio na carteira (valor crescente dos prêmios) e uma menor diversificação de risco da carteira.

\section{RESULTADOS E DISCUSSÃO}

Dentre as seis Unidades Federativas analisadas (Tabela 2), os coeficientes de regressão linear $\left(\mathrm{R}^{2}\right)$ entre sinistros de um ano e prêmios do ano posterior são significativamente distintos de um padrão aleatório de distribuição dos dados (p-valor < 0,05) em Mato Grosso do Sul, Rio Grande do Sul e São Paulo, o que permite inferir ocorrência de seleção adversa nestas UFs durante o período de 2003 a 2013 (Tabela 2).

Tabela 2. Sistematização dos resultados do estudo nas seis Unidades Federativas analisadas

\begin{tabular}{ccccccc}
\hline UF & $\mathbf{R}^{2}$ & p-valor & $\begin{array}{c}\text { Inferência } \\
\text { de seleção } \\
\text { adversa? }\end{array}$ & $\begin{array}{c}\text { Pico do } \\
\text { valor dos } \\
\text { sinistros }\end{array}$ & $\begin{array}{c}\text { Pico do } \\
\text { valor dos } \\
\text { prêmios }\end{array}$ & $\begin{array}{c}\text { Valor dos sinistros superior } \\
\text { ao dos prêmios }\end{array}$ \\
\hline MS & 0,587 & $0,01^{*}$ & Sim & 2012 & 2013 & 2004 a 2006 \\
MG & 0,120 & 0,32 & Não & 2011 & 2013 & 2004 e 2006 \\
PR & 0,224 & 0,17 & Não & 2009 & 2013 & 2004 e 2009 \\
RS & 0,417 & $0,04^{*}$ & Sim & 2012 & 2013 & 2005 e 2009 \\
SC & 0,093 & 0,39 & Não & 2012 & 2011 & $2005,2007,2009$ e 2012 \\
SP & 0,75 & $0,003^{*}$ & Sim & 2012 & 2013 & 2005 e 2008 \\
Coeficiente de regressão linear (R2) entre sinistros de um ano e prêmios do ano posterior; p-valor \\
dos testes estatísticos de aleatorização - (*) indica p-valor < 0,05; inferência da ocorrência de seleção \\
adversa; ano de ocorrência dos picos de valor dos sinistros; e anos em que houve a ocorrência de \\
valores de sinistros superiores aos valores dos prêmios
\end{tabular}

Observa-se na Tabela 2 que os valores estatisticamente significativos de relação entre sinistros e prêmios são exatamente aqueles que apresentam $\mathrm{R}^{2}$ maior. Este resultado é esperado ao utilizar-se a análise de dados por aleatorização, uma vez que com $\mathrm{R}^{2}$ altos, ou seja, onde a reta de regressão explica um percentual alto da variância dos dados, é pouco provável que combinações ao acaso tenham poder explicativo maior ou igual aos dados originais. Com isso, com $\mathrm{R}^{2}$ altos, os p-valores tendem a ser mais baixos. Ressalta-se novamente que os resultados identificados 
como significativos restringem-se ao conjunto de dados analisados, não sendo possível generalizar essas conclusões.

Realizando uma análise comparativa dos três Estados em que se pode inferir a ocorrência de seleção adversa (MS, RS e SP), é possível verificar que, nos três casos, houve um pico do valor dos sinistros em 2012 (Tabela 2), no ano em que ocorreu o fenômeno La Niña (INSTITUTO NACIONAL DE PESQUISAS ESPACIAIS, 2012).

Apesar de o La Niña não se constituir como um fenômeno decorrente da mudança do clima, os impactos gerados por esta anomalia climática são análogos aos decorrentes da mudança do clima global, uma vez que este fenômeno aumenta a ocorrência de eventos climáticos extremos.

Também destaca-se que nos três casos em que as análises estatísticas possibilitaram a inferência de ocorrência de seleção adversa (MS, RS e SP), o pico do valor dos prêmios ocorreu em 2013, no ano posterior ao pico do valor dos sinistros (Tabela 2), corroborando com a hipótese de que, com o aumento da frequência de ocorrência de eventos climáticos extremos, cresce a procura por seguro pelos produtores situados nas regiões mais afetadas por tais eventos.

No que diz respeito aos Estados nos quais não se pode inferir a ocorrência de seleção adversa, Minas Gerais, Paraná e Santa Catarina, é relevante mencionar que o aumento do valor dos prêmios não pôde também ser explicado apenas pela ocorrência imediatamente anterior de eventos climáticos extremos, uma vez que estes Estados não apresentaram picos do valor dos prêmios em anos posteriores aos anos em que se registraram os picos dos valores dos sinistros (Tabela 2).

Deve-se considerar que há outros fatores, não incorporados neste estudo, que certamente influenciam a contratação de seguros nas UFs, como a distribuição dos subsídios ao PSR. A disponibilidade de mais dados na base da SUSEP permitiria um refinamento das análises sobre os parâmetros que caracterizam a seleção adversa (RICHARDS; MICHEN, 1998), sendo eles o aumento médio de risco e a redução da diversificação da carteira. O número de apólices contratadas permitiria identificar o aumento de risco médio, enquanto que o valor das apólices permitiria identificar a diversificação do risco. Há ainda outras variáveis - como tamanho da propriedade, tipo de cultivo e produtividade do cultivo - que permitiriam ampliar a compreensão sobre os fatores que fazem com que os prêmios e sinistros variem.

Entretanto, mesmo em Minas Gerais, Paraná e Santa Catarina, constatou-se a 
ocorrência de eventos climáticos extremos nos anos em que se registraram os picos dos valores de sinistros, o que salienta os possíveis impactos econômicos da mudança do clima na produção agrícola. Em Minas Gerais houve estiagem no início de janeiro e chuvas excessivas a partir do final de fevereiro de 2011 (ACOMPANHAMENTO DA SAFRA BRASILEIRA DE GRÃOS, 2011). No Paraná, entre final de 2008 e decorrer de 2009, houve estiagem, excesso de chuvas e geadas (ACOMPANHAMENTO DA SAFRA BRASILEIRA DE GRÃOS, 2009). Já em Santa Catarina, houve escassez de chuva decorrente do fenômeno La Niña em 2012 (ACOMPANHAMENTO DA SAFRA BRASILEIRA DE GRÃOS, 2012).

Destaca-se, ainda, que ao comparar os valores dos sinistros e dos prêmios pagos no mesmo ano (Tabela 2), constata-se que, em todas as UFs analisadas, há a ocorrência de períodos em que o valor dos sinistros foi superior ao valor dos prêmios, o que, ocorrendo com mais frequência no longo prazo, pode colocar em risco a sustentabilidade financeira das empresas seguradoras.

Mesmo nos casos em que não foi possível se inferir estatisticamente a ocorrência de seleção adversa, ressalta-se a relevância da adoção de medidas de mitigação e adaptação à mudança do clima. Estas são particularmente relevantes ao se considerar que, das 27 UFs brasileiras, muitas, principalmente na região Norte e Nordeste, praticamente não possuem acesso ao seguro agrícola, em parte devido aos altos custos de contratação.

Nessas regiões, onde o seguro privado não é amplamente disponível, fazem-se necessários outros instrumentos para aumentar a resiliência à mudança do clima, com especial atenção para a gestão dos riscos e a adaptação dos grupos mais pobres da população (MARENGO, 2009). As medidas de adaptação focadas nos pequenos produtores (agricultura familiar ou de pequena escala) com menor poder econômico são de fundamental importância na busca pelo objetivo de equidade socioambiental, pois apesar de responderem por $70 \%$ da produção agrícola voltada ao mercado interno (BRASIL, 2017), raramente têm acesso ao seguro agrícola.

O seguro agrícola, sob os cenários futuros de mudança do clima, exige um plano estratégico coordenado entre o setor de seguros e o poder público para lidar, por meio de ações de mitigação e adaptação, com a probabilidade alterada da distribuição dos eventos climáticos extremos (SHEN et al., 2010). 


\section{CONCLUSÃO}

Os resultados sugerem que há ocorrência de seleção adversa no mercado de seguro agrícola no Brasil nos Estados de Mato Grosso do Sul, Rio Grande do Sul e São Paulo, sendo possível inferir que os sinistros ocorridos em um ano influenciam os prêmios pagos no ano posterior.

A ocorrência da seleção adversa, aliada à disponibilidade relativamente baixa de seguro agrícola no Brasil, gera um ciclo vicioso, no qual o aumento no risco de ocorrência de eventos extremos leva a um incremento do valor dos prêmios, que por sua vez implica na permanência apenas dos contratos de maior risco nas carteiras de seguros. O baixo número de clientes e o risco aumentado da carteira de seguros, por sua vez, impossibilitam a redução do valor dos prêmios.

Assim, considerando que a mudança do clima aumenta a frequência e/ ou intensidade da ocorrência de eventos climáticos extremos, os quais possuem potencial de gerar valores elevados de sinistros na agricultura, e que, de acordo com os resultados do presente artigo, possivelmente levam a uma maior contratação de seguros, torna-se fundamental realizar mais estudos complementares sobre a ocorrência de seleção adversa no mercado de seguro agrícola no Brasil, pois este fenômeno pode causar prejuízos ou mesmo, em um cenário extremo, a quebra do mercado de seguros.

Os estudos complementares a respeito da seleção adversa no mercado de seguro agrícola brasileiro dependeriam, entretanto, da possibilidade de replicar a abordagem deste estudo nas demais UFs, o que é inviável na ausência de um volume mínimo de dados históricos na maior parte das UFs.

No contexto atual seria desejável ao menos refinar o presente estudo a partir de séries históricas nos mesmos Estados selecionados, inserindo variáveis simples, como o número de apólices contratadas, o que permitiria avaliar se as respostas no valor total dos prêmios ocorrem em função do aumento do valor médio dos prêmios ou da quantidade de apólices transacionadas. No entanto os dados a respeito do número de apólices transacionadas de seguro agrícola ainda não estão disponíveis nas bases públicas da SUSEP.

Tais estudos poderiam, assim, fundamentar a atuação conjunta do mercado segurador e do poder público na redução da vulnerabilidade dos segurados. 
Isso porque, ao reduzir a vulnerabilidade dos agricultores aos eventos climáticos extremos, reduz-se a probabilidade de sinistros, o que possibilitaria uma redução do valor dos prêmios e, consequentemente, aumentaria o número de produtores com acesso ao seguro agrícola, garantindo assim a viabilidade financeira a longo prazo do setor de seguros. A ampliação da base de segurados, por sua vez, potencializaria a diversificação dos riscos das carteiras das seguradoras, assim como a redução da vulnerabilidade e dos custos de contratação aos produtores agrícolas.

\section{AGRADECIMENTOS}

O segundo autor agradece o apoio financeiro da Fundação de Amparo à Pesquisa do Estado de São Paulo - FAPESP, processo número 2015/03804-9.

\section{REFERÊNCIAS}

ACOMPANHAMENTO DA SAFRA BRASILEIRA DE GRÃOS. Safra 2008/2009, décimo primeiro levantamento. Brasília: CONAB, 2009. 39 p.

ACOMPANHAMENTO DA SAFRA BRASILEIRA DE GRÃOS. Safra 2010/2011, décimo levantamento. Brasília: CONAB, 2011. 42 p.

ACOMPANHAMENTO DA SAFRA BRASILEIRA DE GRÃOS. Safra 2011/2012, décimo levantamento. Brasília: CONAB, 2012. 29 p.

ALMEIDA, W. S. Seguro rural no Brasil: situação atual e perspectivas: Ministério da Agricultura, Pecuária e Abastecimento. 2017. 42 slides. Disponível em: http:// www.sober.org.br/palestra/sober_-_acre_-_mapa_10_33.pdf. Acesso em: 19 jun. 2019.

ANDRADE, L. Os limites e as alternativas para o seguro rural no Brasil. Revista Globo Rural, 24 abr. 2017. Disponível em: http://revistagloborural.globo.com/Noticias/Agricultura/noticia/2017/04/os-limites-e-alternativas-do-seguro-rural-no-brasil. html. Acesso em: 19 jun. 2019.

ASSAD, E. D. Agricultura tropical. In: CONFERÊNCIA REGIONAL SOBRE MUDANÇAS GLOBAIS: AMÉRICA DO SUL, 3., 2007, São Paulo. Anais [...]. São Paulo: USP, 2007. 
BANCO MUNDIAL. Revisão rápida e integrada da gestão de riscos agropecuários no Brasil: caminhos para uma visão integrada. Brasília: Banco Mundial, 2015. $76 \mathrm{p}$.

BOYER, M.; PORRINI, D. The efficient liability sharing factor for environmental disasters: lessons for optimal insurance regulation. The Geneva Papers, v. 33, n. 2, p. 337-362, abr. 2008.

BRASIL. Ministério da Agricultura, Pecuária e Abastecimento. Proagro. Brasília: MAPA, 2014b.

BRASIL. Ministério da Agricultura, Pecuária e Abastecimento. Secretaria de Agricultura Familiar e Cooperativismo. Brasil: 70\% dos alimentos que vão à mesa dos brasileiros são da agricultura familiar. 2017. Disponível em: http://www.mda.gov.br/ sitemda/noticias/brasil-70-dos-alimentos-que-v\%C3\%A3o-\%C3\%A0-mesa-dos-brasileiros-s\%C3\%A3o-da-agricultura-familiar. Acesso em: 2 out. 2017.

BRASIL. Ministério da Agricultura, Pecuária e Abastecimento. Zoneamento Agrícola de Risco Climático. Brasília: MAPA, 2014a.

BRASIL. Ministério do Meio Ambiente. Plano nacional de adaptação à mudança do clima: volume II: estratégias setoriais temáticas: Portaria MMA n ${ }^{\circ} 150$ de 10 de maio de 2016. Brasília: MMA, 2016. 295 p. Disponível em: http://www.mma.gov.br/ images/arquivo/80182/LIVRO_PNA_Plano\%20Nacional_V2_copy_copy.pdf. Acesso em: 19 jun. 2019.

BUAINAIN, A. M.; VIEIRA, P. A. Seguro agrícola no Brasil: desafios e potencialidades. Revista Brasileira de Risco e Seguro, v. 7, n. 13, p. 39-68, abr./set. 2011.

CUNHA, A. S. Um seguro agrícola eficiente. Brasília: UNB, 2002. (Série Textos para Discussão, n. 255).

ECKSTEIN, D.; KÜNZEL, V.; SCHÄFER, L. Global climate risk index 2018: who suffers most from extreme weather events?: weather-related loss events in 2016 and 1997 to 2016. Germanwatch, nov. 2017. 35 p. Disponível em: https://germanwatch.org/sites/germanwatch.org/files/publication/20432.pdf. Acesso em: 19 jun. 2019.

ECONOMIA da mudança do clima no Brasil: custos e oportunidades. São Paulo: 
IBEP Gráfica, 2010. 82 p. Disponível em: http://www.colit.pr.gov.br/arquivos/File/ Publicacoes/Economia_do_clima.pdf. Acesso em: 19 jun. 2019.

GUANZIROLI, C. E.; BASCO, C. A. Managing agricultural insurance in Brazil. Comuniica, v. 4, n. 2, p. 33-43, may/aug. 2008. Disponível em: http://repiica.iica.int/ DOCS/B0724I/B0724I.PDF. Acesso em: 19 jun. 2019.

HADDAD, E. A. Economia das mudanças climáticas. In: CONFERÊNCIA NACIONAL DE MUDANÇAS CLIMÁTICAS GLOBAIS DE SÃO PAULO, 1., 2013, São Paulo. Anais [...]. São Paulo: FAPESP, 2013. Disponível em: http://www.fapesp.br/eventos/2013/09/conclima/10/Eduardo_Haddad.pdf.

HAZELL, P.; POMAREDA, C.; VALDÉS, A. (ed.). Crop insurance for agricultural development: issues and experience. Baltimore: The International Food Policy Research Institute, 1986. 322 p. Disponível em: http://www.ifpri.org/sites/default/ files/publications/hazell86.pdf. Acesso em: 19 jun. 2019.

INSTITUTO NACIONAL DE PESQUISAS ESPACIAIS. Centro de Previsão de Tempo e Estudos Climáticos. Importância do zoneamento agrícola e épocas de plantio de cada município. 2017. Disponível em: http://agricultura.cptec.inpe.br/monit_agricola.shtml.

INSTITUTO NACIONAL DE PESQUISAS ESPACIAIS. Centro de Previsão de Tempo e Estudos Climáticos. Nota técnica sobre a previsão climática de consenso: previsão: trimestre JJA/2012. 2012. Disponível em: http://clima1.cptec.inpe.br/ rclima1/ pdf_notatecnica/Nota_Tecnica_JJA2012.pdf. Acesso em: 19 jun. 2019.

LEGENDRE, P.; LEGENDRE, L. Numerical ecology. $2^{\text {th }}$ ed. Amsterdam: Elsevier Science B.V., 1998. 852 p.

LOTZE-CAMPEN, H.; SCHELLNHUBER, H. J. Climate impacts and adaptation options in agriculture: what we know and what we don't know. Journal for Consumer Protection and Food Safety, v. 4, n. 2, p. 145-150, may 2009. Disponível em: http://edoc.gfz-potsdam.de/pik/get/3951/0/22dcee1660b02453c94a683c895cb221/3951.pdf. Acesso em: 19 jun. 2019.

LOVATELLI, C. $19^{\circ}$ Fórum ABAG - Associação Brasileira do Agronegócio. Agroanalysis, jan. 2011. 
MANAGING the risks of extreme events and disasters to advance climate change adaptation: special report of the Intergovernmental Panel on Climate Change. Cambridge, UK: Cambridge University Press, 2012. 582 p. Disponível em: http://www. ipcc.ch/pdf/special-reports/srex/SREX_Full_Report.pdf. Acesso em: 19 jun. 2019.

\section{MANLY, B. F. J. Randomization, bootsrap and Monte Carlo methods in Biolo-} gy. $3^{\text {th }}$ ed. Boca Raton: Chapman $\&$ Hall/CRC, 2007.

MARENGO, J. A. Impactos de extremos relacionados com o tempo e o clima - impactos sociais e econômicos. Boletim do Grupo de Pesquisa em Mudanças Climáticas - GPMC, n. 8, maio 2009. Disponível em: http://mudancasclimaticas. cptec.inpe.br/ rmclima/pdfs/newsletters/Boletim_No8_Port.pdf. Acesso em: 19 jun. 2019.

MEIRELES, D. S. e. Teorias de mercado e regulação: por que os mercados e o governo falham? Cadernos EBAPE, v. 8, n. 4, p. 644-660, dez. 2010. Disponível em: http://www.scielo.br/scielo.php?pid=\$1679-39512010000400006\&script=sci_arttext. Acesso em: 19 jun. 2019.

MILLS, E. The greening of insurance. Science/AAAS, v. 338, p. 1424-1425, 14 dez. 2012. Disponível em: http://users.clas.ufl.edu/prwaylen/GEO2200\%20Readings/ Readings/Climate\%20change/Climate\%20change\%20and\%20the\%20Insurance\%20 business.pdf. Acesso em: 19 jun. 2019.

MITIDIERI, F. J.; MEDEIROS, J. X. Zoneamento agrícola de risco climático: ferramenta de auxílio ao seguro rural. Revista de Política Agrícola, ano 17, n. 4, p. 33-46, out./dez. 2008.

PANDA, A.; SHARMA, U.; NINAN, K. N.; PATT, A. Adaptive capacity contributing to improved agricultural productivity at the household level: empirical findings highlighting the importance of crop insurance. Global Environmental Change, v. 23, p. 782-790, 2013.

RICHARDS, T. J.; MISCHEN, P. The demand for specialty-crop insurance: adverse selection and inefficiency. Journal of Agribusiness, v. 16, n. 1, p. 53-77, 1998. Disponível em: http://ageconsearch.umn.edu/bitstream/90435/2/JAB16oneC.pdf. Acesso em: 19 jun. 2019.

SANTOS, G. R.; SOUSA, A. G.; ALVARENGA, G. Seguro agrícola no Brasil e o 
desenvolvimento do programa de subvenção ao prêmio. Brasília: IPEA, 2013. Disponível em: http://www.ipea.gov.br/portal/images/stories/PDFs/TDs/td_1910. pdf. Acesso em: 19 jun. 2019.

SCHELSKE, O.; CULLEN, J.; TÜLLER, M.; TRÜB, J. Betting the farm?: agricultural risks in Brazil. Focus Report, jan. 2009. Disponível em: https://www.agriskmanagementforum.org/sites/agriskmanagementforum.org/files/Documents/betting_the farm_en\%5B1\%5D.pdf. Acesso em: 19 jun. 2019.

SHEN, S.; BASIST, A.; HOWARD, A. Structure of a digital agriculture system and agricultural risks due to climate changes. Agriculture and Agricultural Science Procedia, n. 1, p. 42-51, 2010.

SUPERINTENDÊNCIA DE SEGUROS PRIVADOS. Seguro rural. 2014a. Disponível em: http://www.susep.gov.br/menu/informacoes-ao-publico/planos-e-produtos/seguros/seguro-rural. Acesso em: 19 jun. 2019.

SUPERINTENDÊNCIA DE SEGUROS PRIVADOS. SES - Sistema de Estatísticas da SUSEP: opção escolhida: seguros: prêmios e sinistros (UF todas). 2014b. Disponível em: http://www2.susep.gov.br/menuestatistica/SES/premiosesinistrosporuftodas.aspx?id=53. Acesso em: 19 jun. 2019.

THE R FOUNDATION FOR STATISTICAL COMPUTING. R: A Language and Environment for Statistical Computing. Vienna: R Foundation for Statistical Computing, 2017. Disponível em: http://www.r-project.org/. Acesso em: 19 jun. 2019.

THE RISE of brazilian crop insurance. Progressive Farmer, mar. 2014. Disponível em: http://dtnpf-digital.com/article/The + Rise + Of + Brazilian + Crop + Insurance/1631954/196627/article.html. Acesso em: 19 jun. 2019.

WORLD METEOROLOGICAL ORGANIZATION. Annex II: glossary In: WORLD METEOROLOGICAL ORGANIZATION. Climate Change 2014: synthesis report. Geneva: WMO, 2015. p. 117-130. Disponível em: https:/www.ipcc.ch/site/assets/ uploads/2018/05/SYR_AR5_FINAL_full_wcover.pdf. Acesso em: 19 jun. 2019.

Recebido em: 28/05/2018

Aceito em: 14/09/2018 